Int. J. Electrochem. Sci., 14 (2019) $2004-2026$

International Journal of

ELECTROCHEMICAL

SCIENCE

www.electrochemsci.org

\title{
Conductive and Porous SnCu-Coated Carbon Cloth Network for Binder-free Li-Ion Storage Anodes
}

\author{
Venroy Watson ${ }^{1}$, Wete Telama ${ }^{1}$, Yaw Yeboah ${ }^{1}$, Jim Zheng ${ }^{2}$, Egwu Eric Kalu ${ }^{1, *}$ \\ ${ }^{1}$ Department of Chemical and Biomedical Engineering, FAMU-FSU College of Engineering, 2525 \\ Pottsdamer St., Tallahassee, FL 32310 \\ ${ }^{2}$ Department of Electrical and Computer Engineering, FAMU-FSU College of Engineering, 2525 \\ Pottsdamer St., Tallahassee, FL 32310 \\ *E-mail: ekalu@eng.famu.fsu.edu
}

doi: $10.20964 / 2019.02 .01$

Received: 25 July 2018 / Accepted: 16 November 2018 / Published: 5 January 2019

\begin{abstract}
Large volume change occurs during lithiation/delithiation of Sn anodes and result in pulverization, poor cycling, capacity loss and anode degradation that impedes the general use of Li-ion batteries. This study proposes a time-controlled synthesis approach for 1-D $\mathrm{SnCu}$ nanoparticles on three-dimensional anode by electrolessly adhering $\mathrm{Cu}$ to $\mathrm{C}$ cloth and subsequently $\mathrm{Sn}$ on the $\mathrm{Cu}$. After annealing at $200{ }^{\circ} \mathrm{C}$, electrically conductive, porous, flexible and mechanically stable $\mathrm{CuSn}$ alloy anode results. The $\mathrm{CuSn}$ anodes exhibited high conductivity due to copper deposit, accommodated volume changes and stress due to both 1-D-deposit and porosity and have high electrochemical activity due to large surface area. After 100 cycles, the sample deposited for the shortest time $(1.5 \mathrm{~min})$ interval and close to 1-D $\mathrm{SnCu}$ deposit has a specific discharge capacity of $\sim 605 \mathrm{mAh} \mathrm{g}^{-1}$ which contrasts to the $\sim 400 \mathrm{mAh} \mathrm{g}^{-1}$ obtained for the sample deposited for $6 \mathrm{~min}$. The specific electrode surface area of the $1.5 \mathrm{~min}$ sample was 169 $\mathrm{m}^{2} \mathrm{~g}^{-1}$ in contrast to $6.4 \mathrm{~m}^{2} \mathrm{~g}^{-1}$ obtained for the 6 min sample. A rate capability of $520 \mathrm{mAh} \mathrm{g}^{-1}$ at a current density of $583 \mathrm{~mA} \mathrm{~g}^{-1}$ was achieved for the thinnest deposit. The porous $\mathrm{Sn}$ anode materials demonstrated low resistance during electrochemical impedance analysis and showed high reversible redox reactions during cyclic voltammetry tests. The achievement of high capacity anode (comprising of $\mathrm{Sn}-\mathrm{SnO}_{2}-\mathrm{Cu}_{6} \mathrm{Sn}_{5}$ ) with good reversible capacity retention through electroless coating method indicates that electroless deposition on flexible free-standing and porous substrate is an effective $\mathrm{Sn}$ anode fabrication technique.
\end{abstract}

Keywords: Sn anode; Electroless deposition; $\mathrm{Cu}-\mathrm{Sn}$ alloy; cyclability; binder-free FULL TEXT 
(C) 2019 The Authors. Published by ESG (www.electrochemsci.org). This article is an open access article distributed under the terms and conditions of the Creative Commons Attribution license (http://creativecommons.org/licenses/by/4.0/). 